University of Nebraska - Lincoln

DigitalCommons@University of Nebraska - Lincoln

To Improve the Academy

Professional and Organizational Development Network in Higher Education

1998

An O.P.E.N. Approach to Learning

Keith Kelly

Roberta C. Teahen

Follow this and additional works at: https://digitalcommons.unl.edu/podimproveacad

Part of the Higher Education Administration Commons

Kelly, Keith and Teahen, Roberta C., "An O.P.E.N. Approach to Learning" (1998). To Improve the Academy. 407.

https://digitalcommons.unl.edu/podimproveacad/407

This Article is brought to you for free and open access by the Professional and Organizational Development Network in Higher Education at DigitalCommons@University of Nebraska - Lincoln. It has been accepted for inclusion in To Improve the Academy by an authorized administrator of DigitalCommons@University of Nebraska - Lincoln. 
Kelly, K., \& Teahen, R. (1998). An O.P.E.N. approach to learning. In M. Kaplan (Ed.), To Improve the Academy, Vol. 17. (pp. 327-348). Stillwater, OK: New Forums Press and the Professional and Organizational Development Network in Higher Education. Key Words: computer assisted instruction, cooperation, distance learning, faculty development programs, faculty role, individualized instruction, nontraditional students, two-year colleges.

\section{An O.P.E.N. Approach to Learning}

\section{Keith Kelly}

\section{Roberta C. Teahen}

Northwestern Michigan College

O.P.E.N. Learning, an open-entry, open-exit delivery system that is supported by a computerized instructional management system and an extensive learning team, is a fundamental restructuring of the approach to education. This article summarizes the rationale for eliminating the traditional calendar by framing an educational system around a performance-based approach.

Educators have always known that students learn at different paces, yet school calendars have continued to be divided into semesters or quarters. Efforts over the years have attempted to meet the challenges of diverse learning styles, yet classrooms are still largely teacher centered. Innovations designed to address the differences among learners have been sporadically attempted, yet wide-scale education reform at the collegiate level remains elusive. Developments of the last decade, however, promise to propel education in new directions, many of which have the potential to address the shortcomings we all can identify. 
One such direction that holds promise is the elimination of the time-based model and replacement with a competency-based one. This notion is not new, having been tried many times in many forms over the years, with learning packages, modular instruction, correspondence courses, and more. However, today's technology provides an additional opportunity to creatively address asynchronous learning.

We frame the delivery options with the following matrix, which illustrates some of the emerging strategies and how each relates to time and place. Much of "traditional" instruction is both time and place bound, while O.P.E.N. (Options for Performance-Based Education Now) Learning eliminates the time binds but is thus far, in our example, somewhat place bound.

\section{FIGURE 1 \\ Instructional Delivery Options}

\begin{tabular}{|c|c|}
\hline O.P.E.N. Learning & Web-Based \\
\hline Same Place & Different Place \\
Different Time & Different Time \\
\hline Same Place & Different Place \\
Same Time & Same Time \\
\hline
\end{tabular}

Traditional Classroom Instruction

Interactive Television

The purpose of this paper is to explore one college's experience with the implementation of a "time-sensitive, competency-based" curriculum for Michigan citizens. In response to a Michigan Department of Education grants competition, Northwestern Michigan College proposed to design a program that would use technology extensively in two major ways: for computer-mediated instruction and as an instructional management system. O.P.E.N. Learning is the term used to identify courses that are offered in this open entry/open exit format. "OPEN" seemed most descriptive of the philosophy underlying this system, and the necessary emphasis upon a competency approach in such a learning environment led to the extended name: 
Options for Performance-Based Education Now. A rationale for the O.P.E.N. Learning approach follows.

\section{The Need}

Reviewing the education reform landscape, writer Terry O'Banion, executive director of the League for Innovation in Community Colleges, states that "the Carnegie unit is but the tip of a very large iceberg that has frozen education into a structure created for an earlier social order" (O'Banion, 1997, p. 8). Schools were designed to accommodate the needs first of an agricultural era, with its free summers and early afternoon dismissal designed to allow students to participate in the farm chores and the harvest responsibilities. The calendar persisted when education moved to the industrial model of mass production -the same education for every student. The "mass production" approach has endured, in spite of some tracking and special programs that have developed over the years, such as special population services, honors programs, or career tracks.

During this period, the educational needs of college students, particularly in the community college sector, have become increasingly complex and diverse. An increasing number of minority students, individuals with special needs, students from different cultures or nations, and others with multiple responsibilities populate our campuses. It is a minority of community college students who view themselves primarily as students. The majority have multiple life roles as employees, often full time; parents, often single parents; community contributors; spouses or significant others; and in other roles. Patricia Cross refers to these students as those who have a "blended life plan." By this, she means "to suggest that work, education, and leisure are concurrent, rather than alternating, at all points throughout life" (Cross, 1981). In 1998, the College Board conducted a national study of adult learning in America. Among their findings are the following:

Adult students - those students 25 years of age or older-now make up close to 50 percent of all college enrollments in the U.S. This represents a 50\% growth rate of adult students in the past 20 years-a major factor in the steady rise in college enrollments over recent decades... from 8.5 
million in 1970 to an expected 15 million by 2000 . Traditional-aged students are no longer the norm on American campuses.

The typical adult student is a white, 33-year old female, working full time ( $65 \%$ of adult students are women)... Although working and managing families, $30 \%$ of all adult students study on a full-time basis... Adults enroll in shorter, faster-paced courses as often as they enroll in traditional-length, 15-week courses... At the undergraduate level, 50\% study at a community college and $50 \%$ at a four-year college (Aslanian, 1998).

The several-day-per-week, 15-16-week-per-semester, two- or threesemester-per-year format is simply not convenient for many; yet, the schedules today in most institutions look much like those of a generation ago, when students attended college full time. This is not to suggest that schedules are not beginning to reflect a greater proportion of evening, weekend, and short-format offerings, but these are generally the exception rather than the rule.

Not only is the schedule not convenient, but the formats are often not conducive to learning. Walk by many classrooms on campus today and observe the engagement level of the students. For many, education is a passive activity. At the same time, much research supports the value of active learning. Active learning means more than a hands-on experience, or a group activity, as some have mistakenly interpreted the concept. It means engagement. In a position paper of the Joint Task Force on Student Learning, the authors write that "active participation by the learner is essential for productive learning, dictating that...students be expected to take responsibility for their own learning" (American Association for Higher Education, et al., 1998).

There is a lack of common definition of active learning. However, there is general agreement that to qualify as active learning, students must do more than listen. "They must read, write, discuss, or be engaged in solving problems" (Bonwell \& Eison, 1991). A 1984 report, one of several that have attempted to influence higher education, was aptly titled Involvement in Learning. This publication by the Study Group on the Conditions of Excellence in American Higher Education highlights the importance of engagement when it states:

The amount of student learning and personal development associated with any educational program is directly proportional to the quality and 
quantity of student involvement in that program (Study Group, 1994, p.19).

The Study Group concludes that the most important skills individuals should develop for the next century is that they should have "learned how to learn" (Study Group, 1994, p. 81). Many of the recommendations in the 1984 report comprise the higher education agenda of the late 1990s. A more flexible approach that increases students' responsibility for their own learning is a powerful combination for involving students and enhancing their learning.

An American Imperative also recommends "putting student learning first." In this 1994 document, the authors write:

Putting learning at the heart of the enterprise means campuses must: ...tailor their programs - curriculum, schedules, support services, office hours - to meet the needs of the students they admit, not the convenience of staff and faculty (Wingspread Group, 1993, p. 13).

The rise in the number of available correspondence courses, on-line courses, telecourses, and business-sponsored college courses should be sufficient evidence of the desire among many of those we propose to serve for another delivery system. The dramatic rise in the enrollments of the University of Phoenix is singular testimony to this market demand. With what we know about learning styles, individual differences, and cognitive theory, most educators should acknowledge that time has been both arbitrary and capricious as an educational construct. The time has long since passed for the predominance of a calendar-based or seat-time model. In 1992, a commission was appointed to study this issue, and its widely publicized work coined the term "Prisoners of Time." The National Education Commission on Time and Learning observed:

Unyielding and relentless, the time available in a uniform six-hour day and a 180-day year is the unacknowledged design flaw in American education. By relying on time as the metric for school organization and curriculum, we have built the learning enterprise on a foundation of sand (National Education Commission on Time and Learning, 1994, p. 7, cited in O'Banion, 1997, p. 10).

Although this study primarily focused on K-12 education, with its 180-day years, collegiate schedules are minimally different. In con- 
trast, O'Banion identifies several building blocks for constructing a learning college. His recommendations include improved assessment, collaborative learning, active and contextual learning, and "expanded and more flexible structures as expressed in open-entry/open-exit, distance learning, information networks, and differentiated staffing" (O’Banion, 1997, p. 234).

The time is past due for American education to respond to the known changes in our clientele, our heightened awareness of learning issues, and the need for improved and expanded delivery options. One such delivery option, O.P.E.N. Learning, is the focus of this paper.

\section{The Instructional Management System}

Central to the development of the O.P.E.N. Learning system is an instructional management system that enables a more individualized approach for learners. One of the greatest challenges faced by instructors who attempt to adopt a more individualized approach to teaching is the difficulty of "keeping track" of students' progress. Dubbed the "AIM system," which stands for Asynchronous Instructional Management, this intranet software system has student and instructor components. Students may access the system to log into courses, change their passwords, view their grade records, communicate with their instructors, or check their progress against their individual learning plan. The instructor system manages student and course information, provides an electronic grade book, and generates an extensive array of reports. Weekly status reports inform both the instructor and the student of progress made. Additional enhancements for both the students' and the instructors' packages are planned.

\section{A Learner Focus}

Students may enroll for the courses on almost any day of the week throughout the calendar year, although the majority are still enrolling at the traditional start dates of the semesters. (Financial aid regulations and institutional practices are important factors affecting time of enrollment.) The first student responsibility is the completion of an orientation program. At the beginning of semesters, several group sessions are conducted by the faculty, where students meet the instruc- 
tor(s), tour the facility, develop their learning contracts, and learn about the opportunities and challenges associated with self-directed learning. Outcomes of the orientation session include the development of a learning contract with start and end dates and a time management plan that captures the other time commitments of the student and identifies times planned for work in the Center for Learning, which will be described later.

Students are encouraged to commit to a specified number of hours per week, a figure that is calculated based on the average time for course completion and the individual's projected end date. When students have not met their time objective and the corollary learning accomplishments, encouragement notices are sent to the student. These students are easily identified by the AIM system in a process that is far less labor intensive than hand-kept grade books would require.

When learners enroll after the group orientation sessions or have conflicts that preclude participation, they may complete an individualized, computer-based orientation or make an individual appointment with an instructor or learning coach, and then complete the required documents. This individualized option is becoming increasingly common, as the flexible enrollment opportunities for O.P.E.N. courses are becoming better known.

The importance of setting goals, meeting objectives, managing time, and keeping a long-term perspective in mind are all highlighted in the orientation. The session focuses on the importance of emotional intelligence for self-directed learners. Building on the perspectives of Goleman and others who are exploring the role of emotional intelligence in individual success, the orientation program attempts to illuminate how individuals may control their destinies through goal setting, self-motivation, and taking charge of one's emotional life. Goleman writes:

Now science is finally able to speak with authority to these urgent and perplexing questions of the psyche at its most irrational, to map with some precision the human heart. This mapping offers a challenge to those who subscribe to a narrow view of intelligence, arguing that IQ is a genetic given that cannot be changed by life experience, and that our destiny in life is largely fixed by these aptitudes. That argument 
ignores the more challenging question: What can we change that will help our children fare better in life? What factors are at play, for example, when people of high IQ flounder and those of modest IQ do surprisingly well? I would argue that the difference quite often lies in the abilities called here emotional intelligence, which include self-control, zeal and persistence, and the ability to motivate oneself (Goleman, 1995, pp. xi-xii).

This emotional intelligence approach to orientation for O.P.E.N. Learning was selected following a thorough review of learning styles research, which was dismissed for this instructional design since it was not our plan to alter the delivery for individual differences but rather to alter only the pace. Just as lecture is not right for each student, neither is a more self-directed approach appropriate for every student. Yet, "self-direction" is the cornerstone of this design, and our challenge was to equip students to meet the expectations of a system that relies more heavily on students' planning and motivation. Our quest to achieve this continues.

Central to the delivery strategy for O.P.E.N. Learning is a Center for Learning. New to this campus, but available in many forms on many campuses, this "place" provides a context for the connections between students and staff. Although much of the students' work can be completed at remote sites, and more will be possible in the future, some tasks require their participation on the campus. At present, all learners must complete tests on-site. We estimate that about 80 percent of the enrollees complete most or all work on site because of the extensive hardware, software, and learning support that is available. Our twice-per-hour use statistics also reveal that students are electing to come in greatest numbers at times when the O.P.E.N. instructor is available in the Center, even though few find it essential to their progress.

The Center is located in the college library and offers 50 computer workstations that are fully equipped with a wide range of software, including software required for the O.P.E.N. courses. The Center is open 80 hours per week and is staffed at all times with personnel of different classifications and expertise who are available at different hours of the week. Staff expertise is generally communicated to students both informally and through posted schedules. There are 
usually two individuals available to the "floor" during most of the 80 hours each week. Staff include learning professionals, such as the Director of the Instructional Support Center and the Director of the Center for Learning; a faculty coordinator (a regular faculty person from the health discipline), who is in the Center half time and is the individual responsible for development of general instructional materials and staff scheduling; regular NMC faculty who take one or two office hours in the Center each week; learning coaches (a paraprofessional classification, but one of our three coaches is a fully qualified science instructor and two others are computer experts); and student assistants who have demonstrated helping skills, interpersonal abilities, and other diverse abilities. Up to 1,000 visits were recorded during some weeks in the first year of operation. For 40 hours each week, an O.P.E.N. instructor is on duty in addition to another Center staff member. For the other 40 hours per week, learners may complete O.P.E.N. assignments, but they do not have the advantage of access to a course instructor. However, the other staff are able to lend general learning support, and many are well acquainted with the content in the current offerings. As more classes become available, this situation cannot be sustained, because it is unlikely that we will find staff members equally versatile in computer applications, math, science, English, foreign languages, etc. We have implemented what Dr. O'Banion speaks of when he refers to "differentiated staffing," where individuals are not role-bound, and we can demonstrate that it can be a highly efficient and effective approach.

The advantage of the Center approach is that students have access to an instructor for $\mathbf{4 0}$ hours per week, far more than students would normally have in a traditional college course. Traditionally, a student enrolled in a 3-credit course would have access to the instructor just three hours, as one of 20 or more students in the class. Having a fully-staffed facility for 80 hours per week is also more advantageous than has historically been possible.

There are difficulties in maintaining such high levels of staffing, including costs and definitions of faculty load, which are reviewed later, as well as issues of teaching style and curriculum design. Facilitating a large number of learners who are at various stages of the course is a teaching challenge. Instructors are genuinely "coaches" in 
this instructional environment. Having "control" of one's class in the traditional sense is no longer possible. There are some students who may never meet their instructor. Security issues are addressed by verification of identification at all testing periods with picture IDs. Instructional design suited to O.P.E.N. Learning is another critical competency. We have discovered that there are few instructors who have experience with building full courses with objectives, pre- and post-assessments, etc. Some honestly admit that they do not know how to create a course-just to implement one that has already been developed. Just as O.P.E.N. Learning is not right for every student, it is not right for every instructor. One way in which we have addressed teacher differences is to assign different responsibilities. Some teachers are course developers and others are course instructors; some do both.

\section{The Courses}

In the first year of the program, eight skills-based courses were available in the office and computer information systems areas. Certainly, these courses lend themselves well to a computer-mediated approach, which is the principal delivery method. Utilizing commercial software and instructor-developed learning packages, students progress at their own pace through the materials by using a combination of tools: computer learning packages, the actual software (such as Word and Excel), texts, and the assistance of learning coaches, student assistants, and instructors.

The entire two-year electronics program is in its fourth year of operation and offers 19 courses. During the 1998-99 academic year, additional courses from communications, health, technical math, and business will be introduced.

\section{Internal and External Institutional Systems}

It will come as little surprise to most readers that one of the biggest challenges to an innovative approach to delivery relates to internal process issues. Among these are crafting new refund policies, adapting enrollment policies, considering financial aid ramifications, instituting different grading practices, and redefining faculty load. Few 
colleges or state and federal agencies are designed to meet the challenges of a completely flexible system. Although we have adequately addressed these problem areas, there remains more to be done in encouraging the development of alternative approaches. Two examples of changes made or in process at NMC to accommodate O.P.E.N. learning will help to illustrate the problems.

Perhaps the greatest barrier-because of its federal legislation limitations - concerns financial aid. This funding source, a part of the Higher Education Act, is accessed by about 40 percent of our students. Developing a system that complies with federal law and meets students' needs is critical. The federal financial aid guidelines are still calendar, clock-hour, and place bound (although there is some optimism that changes will be forthcoming as more virtual courses are offered). The calendar issue can be addressed with a clock-hours definition of a course rather than credit hours. Students accessing financial aid must also be making satisfactory progress, and institutions determine what criteria they will use and how frequently they will do this monitoring during an academic year. It is possible to evaluate students' progress once per year, rather than the twice-per year procedures of some colleges. By design, many students will have an Incomplete grade at the end of a traditional semester. By some financial aid practices, this student would be determined not to be making satisfactory progress. We have proposed the addition of an IP (In Process) grade that should be considered as "satisfactory" progress in financial aid reviews. Refund practices have been changed for O.P.E.N. enrollees with refunds now being computed according to the contracted start date, a date that is fully accessible to financial aid staff and other administrators through the A.I.M. system's administrative applications. One major product of the final project report will be specific institutional and public policy recommendations concerning these matters.

Although it has not been the biggest issue at NMC, the first question raised by outsiders has been the issue of faculty load. We have temporarily redefined the load of a regular faculty member, the person who is the primary architect of the courses to date. We have redefined the responsibility of adjunct instructors when their role in the Center does not include course development, presentation, and/or 
grading. We have also hired Learning Coaches, a para-professional classification, for supplemental instruction. During the first semester, our delivery system was more costly than the traditional would have been. However, by the second semester, with increased enrollments, the economies of scale began to pay off, and the system is now more cost-effective than comparable traditional offerings. The dual issues of "load" in the concerns of the faculty and of "costs" in the minds of administrators are essential to address but can be resolved in mutually beneficial ways.

Although we have not institutionalized the definitions and may continue to be challenged by our redefinitions, we offer the following as examples of ways in which we have addressed the load question to date at NMC. First, a regular faculty member was provided half-time release to develop the courses-a total of 11 credits and 6 courses. This instructor has also served as the primary lead instructor for delivery. Her "teaching" load has been defined by student credit/contact hours generated rather than by credits. At NMC, the minimum class size is 14 . Occasional exceptions exist for sequence courses, advanced courses, etc. The average class enrollments in comparable classes prior to O.P.E.N. was 17 , which we established as the minimum enrollment number for each credit. A standard faculty load at NMC is 15 or 16 credits. We established this instructor's base at 16 . By establishing our minimums above the college minimums, we anticipated administrative support for this innovation, which we received. For a full-time instructor, 16 credits times an average enrollment of 17 results in a minimum enrollment standard of 272 student credits/contact hours. A half-time teaching assignment in the Center would require half this number, etc. For a full-time Center (O.P.E.N.) assignment, the regular instructor is expected to be available a minimum of 20 clock hours (versus the 15-16 of a regular faculty load). In the first and subsequent semesters, the identified load targets were exceeded. The challenge we will face in fall 1998 is the situation where a single specialty course is offered, because there will not be other classes to make up for shortfalls. In the first year, some courses were offered with less than 14 enrollees, because there were other courses enrolling above the minimum. This advantaged both the instructor and the students, since in other semesters the students would not have been 
able to take the course, and the instructor would have been required to pick up another class- "bumping" an adjunct faculty member and disrupting the schedules of the instructor and others.

In the first semester, the adjunct faculty had redefined workloads. Because they were not responsible for course development or grading, they agreed to work two hours in the Center for each credit hour of payment. Typically, they would earn twice as much per hour for contact time, but they would have considerable out-of-class preparation work. The adjunct faculty considered this a fair trade and agreed to the two-for-one arrangement. By the second semester, the enrollments had mushroomed so that the lead instructor was having difficulty keeping the grading current, and one instructor was added as the instructor of record for some classes and was paid the usual adjunct rate. By the third semester (summer), two adjuncts had assumed all of the teaching responsibilities, because of the regular instructor's choice not to teach in the summer. She will return for the fall of 1998, but with the enrollment patterns now established, we anticipate that the adjuncts will also be required in an instructional role rather than as Center O.P.E.N. staff at a two-for-one basis. In fact, utilizing the prorated student-credit-hours formula, the adjuncts actually earned more during the summer than they would have if they had taught the same classes traditionally, which was obviously appealing to them and still fiscally responsible for the college. It is important to note here, even though it will be discussed more in another section, that the total enrollments in the summer semester in comparable classes more than doubled from the prior year because of the O.P.E.N. options. Overload has not been utilized yet, although a tentative formula has been crafted. In our environment, few faculty choose to take overload when it is available, so extra enrollees have been assigned to other instructors.

For the development of fall 1998 courses, the instructor developers are being paid $\$ 1,000$ per credit in overload compensation for one time only. For a three-credit course, the instructor will be paid $\$ 3,000$ for development and then will have their teaching hours/load counted according to the students-per-credit formula, with the minimum established according to the previous average enrollment in the course. This development rate is above the top overload or adjunct pay rate per credit, but our grant availability allowed us to offer extra incentives 
for additional course development. In the future, the number of credits in the course will be paid at the usual overload rate, as is customary for other flexible-learning options (F-L-O).

\section{Evaluation}

"Closely watched trains" is the metaphor used by our assessment consultant on this project. Because it is an externally funded project that requires evaluation, there is more evaluation being conducted on these students and courses than has ever existed for any others in the college. Students are interviewed at the start of a course, throughout the course, and after a course is completed. Grade distributions are reviewed and compared with those in the traditional delivery system in comparable time periods. Highlights of our findings are summarized here.

Perhaps the most visible symbol of learners' satisfaction is their enrollment. During the first semester, enrollments in O.P.E.N. courses surpassed enrollment in equivalent traditional courses by $60 \%$. This disparity continued to expand during the second semester with O.P.E.N. enrollment at $380 \%$ of traditional. In the summer of 1998 , enrollments more than doubled the prior year's enrollments in the same courses. Enrollment in O.P.E.N. courses dramatically increased in every semester. As noted earlier, summer enrollments were up over 100 percent, but enrollment increases for individual courses throughout the year ranged from 5-100 percent, at a time when the college's overall enrollments have been flat. Almost one-third of the enrollees in the fall semester enrolled for the course after "final registration," representing nearly a 50 percent increase in enrollments in these classes after the beginning of the semester. In other years, this option would not have existed. (Note that the term "final registration" has little meaning in an O.P.E.N. environment, yet it drives many administrative practices, including official count dates, which must be moved to the end of semesters.) The rise in enrollments for these courses, particularly when very little advertising has been done, is spectacular.

Students were uniformly grateful -at times even delighted-by the availability of O.P.E.N. courses. Most noted that the reason the 
course was attractive to them was because of their complicated life schedules. In a spring 1998 survey, 63 percent of enrollees gave "flexible weekly schedule/attendance" as their primary reason for selecting an O.P.E.N. course. An additional 18 percent cited "selfpaced learning and work" as their reason. Almost half (48\%) were looking to increase skills and an additional 20 percent cited program requirements as what they were looking for in O.P.E.N. Forty percent anticipated no challenges in completing their work. Staff, however, have discovered that these very complicated lives also made it difficult for learners to keep time commitments. In a college-wide survey of all students, 17 percent expressed a desire for more O.P.E.N. courses, the flexible learning option that enjoyed the highest support among the flexible options offered (including on-line, Web-based courses; interactive television courses; and telecourses, all of which are under simultaneous development at NMC).

At the end of the first semester, almost one third of the students in some courses were incomplete, even though their personal plan had been to complete by that date. However, many learners were "back at it" during and after the semester break completing their learning objectives. A review of the completion rates for fall semester, a semester later, reveals that only 43 percent of the fall enrollees with Incomplete grades had completed these courses with grades above 0.0 by the end of the next semester. We anticipate that these numbers will improve for spring enrollees, since a much more aggressive follow-up initiative was developed, where students who fell behind plan in any week received a letter from their instructor advising them of their status and encouraging their progress. When students failed to be back on track by the third week (following repeated letters), they were advised that they would be dropped from the class if they failed to make contact with their instructor for a consultation about their progress. It is important to remember that the plan against which the student is being tracked is his or her plan-not the instructor's. If the student had elected a slower pace, the tracking would be evaluating progress against this pace-not an arbitrary semester standard.

When compared to overall success rates, O.P.E.N. learners do comparatively well. In analyzing successful completion rates, we have used the concept of "critical ratio" to identify the relative numbers of 
successful completers. Because the curriculum is competency-based, we have established a 2.0 as our minimum standard for successful completion. In one cluster of courses, 36 percent (a critical ratio of .36), in a group of 106 students, did not achieve a 2.0 or higher. In contrast, the traditional courses had a critical ratio of .25 (25 percent who did not achieve the 2.0 or above), in an enrollment of 25. Many are selecting the self-paced courses because of their life circumstances, and at this time we have inadequate data to contrast the populations who choose O.P.E.N. versus the traditional, but we suspect there are important differences. We caution readers who are concerned about these success rates to take into account the rates that have existed on their own campuses. Because O.P.E.N. students often take an Incomplete path rather than a withdrawal path, the O.P.E.N. statistics may appear worse than traditional courses. One must take into account the numbers of students who have withdrawn from classes prior to receiving a failing or low grade, which our critical-ratio approach does. Although not a comparable course, we consider that there is some validity in looking at other low-level courses, such as beginning algebra, to see what levels of performance are common with community college outcomes data. In traditional, beginning algebra courses during 1998, 58 percent (critical ratio of .58) of the students did NOT earn a 2.0 or higher. Low success rates are commonplace in many colleges and in many classes, which is not to suggest that we should not be concerned about similar rates in O.P.E.N., but to argue that we must look at all courses and other factors, such as improved access and meeting needs of diverse constituencies, in making determinations about success. We are confident that high-achieving students are able to achieve at high levels in O.P.E.N. classes. In the cluster of $116 \mathrm{~A}, \mathrm{~B}$, and C courses, 32 percent earned 4.0 grades in the O.P.E.N. format, while only 12 percent earned a 4.0 in the traditional courses. Our future study will attempt to understand the differences between the high- and low-achievers in O.P.E.N. courses.

Because O.P.E.N. is not appropriate for every learner, our design had anticipated that all courses would continue to have a traditional option. Regrettably, in the opinions of many, the O.P.E.N. option had the result of killing some traditional delivery courses by spring and summer, because the traditional courses did not attract the minimum 
numbers. As a result, some students were forced into the O.P.E.N. option if they wanted the course. Some faculty have consequently become more skeptical about O.P.E.N. Learning because of the impact it could have on their own courses. For high-enrollment, multiple-section courses, this should not be a problem. It is clear, however, that O.P.E.N. courses are preferred by many of our students. Skepticism also surrounds the high number of Incompletes, an area of concern to the O.P.E.N. Learning team as well. We do not find the preliminary data troubling, however, since we have attracted large numbers of students who otherwise had little or no access and who may be fundamentally different from traditional enrollees. We are likewise cautionary about the fact that we have only one year of experience with this specific approach, and we are making daily adjustments to assure increasingly higher levels of success. Finally, we also do not yet have comparative data on other flexible-learning options, such as on-line courses, etc. We anticipate that O.P.E.N. will enjoy greater successes than other options because of the extensive availability of instructors on site.

Learners are very positive about the course packages. They find them easy to use, thorough, and clear. Learners appreciate the clarity of learning objectives and the standards for successful completion. When learners progress at their own pace, and perhaps never interact with the primary instructor, it is essential that the courses be developed comprehensively.

An end-of-semester evaluation by students in fall courses rated all aspects of the course from 4.0-4.9 on a 5.0 scale on questions concerning learning gain, flexibility, help from staff, learning materials, feedback from instructor, Center hours, and motivation levels.

More personally, two students offered the following comments when interviewed by staff of The Business News.

"You can come anytime you want and there's always somebody here to help if you have a problem."

"You do have to be motivated, but I really like being able to work at my own pace."

Many other highly favorable comments were captured on videotape by the college's TV production staff when they circulated through the 
Center asking for student comments. All except one student have been very positive about the development, and this one student admits to an inability to schedule the required time to complete course assignments.

\section{Collaboration}

An additional feature that has played an important role in the success enjoyed to date in the project is collaboration among staff and with the external community. The instructional team is comprised of faculty members from the areas of electronics, business, communications, health, and the Center for Learning. The diverse disciplinary perspectives has added more depth to our development of course templates, learning standards, faculty load, and more. We have designed throughout to accommodate courses beyond the initial several, with practices that would accommodate any college course or instructor. Each team member assumed responsibility for different aspects of the project, but the rich diversity of their disciplinary backgrounds provided great strength to the project. The same team is developing the next several courses. Individuals from the Enrollment Management Division have also been instrumental, as financial aid, enrollment, count-date, and other administrative practices had to be tackled. Regular meetings were held in the first year with enrollment-management staff to grapple with these issues. Some glitches still exist, and continuing conversations are allowing us to resolve each problem as it arises. College Relations staff have been helpful in offering assistance with paid advertising and article production. The counselors and advisors have sought to understand the offerings and advise students appropriately. Advisors have been key in promoting the courses, as they help students build schedules that fit their busy lives. O.P.E.N. Learning often meets students' time restrictions. A positive, can-do attitude on the part of the administrative and professional staff of the college is essential.

Studies of teams note that establishing a productive working relationship is often only accomplished on long-term, shared-goal assignments. O.P.E.N. Learning has been an exemplary model of teamwork. Its presence is a major factor in the success of the O.P.E.N. 
system. This multi-disciplinary, multi-department collaboration serves as a reminder of, as well as a model for, the process by which other innovations will need to advance within a traditional academic environment. Innovation is far more likely to spread when it enjoys widespread participation in several different areas rather than being restricted to one area.

Collaboration extended beyond our campus and included a partnership with the local workforce development agency. This partnership enabled us to identify clients for the program and to learn how we could best meet the needs of the employed and those preparing for return to paid employment through welfare-to-work and dislocatedworker programs, among others. Based on our initial work, it seems that community support for a more flexible approach will be very high. The Michigan Department of Education was another critical partner, as they supported our team's work and provided opportunities for us to share our preliminary work with other state agencies. A recent Michigan Jobs Commission technical-training center RFP has called for the implementation of open-entry, open-exit curricula in the proposals for funding of centers. The resources committed by Michigan to the development of O.P.E.N. or flexible learning options are sure to result in its gaining widespread acceptance throughout the state. The work we have done to date will not only serve us well in this venture, but should also provide a rich resource base for others.

Our efforts were encouraged by a local newspaper editorial that followed a front-page story about the development and acknowledged what we have also learned about its applicability for different audiences. The editors wrote:

What makes this new approach at NMC so exciting is the recognition that students come with all sorts of needs and all sorts of schedules. Not all can work at their own pace, not all would be well served by this type of learning. But for those who can handle the responsibility, this type of thinking will make college courses and college degrees a reality that was virtually impossible a few years ago (“Our View," 1997).

\section{Conclusion}

The American Imperative suggests: 
We must redesign all of our learning systems to align our entire education enterprise with the personal, civic, and workplace needs of the 21st century... These changes demand that American education transform itself into a seamless system that can produce and support a nation of learners, providing access to educational services for learners as they need them, when they need them, and wherever they need them. (Wingspread Group, 1993, p. 13)

O.P.E.N. Learning is already addressing much of this challenge, providing access "as students need it" and "when they need it." Our next phase of development will seek to address the challenge of access "wherever" they need it, to move to the upper-right quadrant of our matrix where neither place nor time is a limiting factor. As we move, the strength of the current delivery system's high levels of support must move with us, because not all of our learners have developed the skills essential for self-directed, lifelong learning.

\section{Additional Information}

Because this development has been funded by a Michigan Department of Education grant, copies of the course and software materials developed for the project are available for a nominal cost. Additional information about O.P.E.N. learning can be gained by reviewing our website (which is under continuing construction) at:

http://its-nt.nmc.edu/openlearning or by contacting the authors for additional information.

\section{References}

American Association for Higher Education (AAHE), the American College Personnel Association (ACPA), \& the National Association of Student Personnel Administrators (NASPA). (1997). Joint Task Force on Student Learning Final Report [Online]. Available: http://www.aahe.org/assessment/joint.htm

Aslanian, C. (1996). Highlights from adult learning in America-why \& how adults go back to school. [Online]. Available: http://www.collegeboard.org

Bonwell, C., \& Eisen, J. (1991). Active learning: Creating excitement in the classroom. ERIC Digest.

Cross, K. P. (1981). Adults as learners-increasing participation and facilitating learning. San Francisco: Jossey-Bass.

Goleman, D. (1996). Emotional intelligence-why it can matter more than IQ. New York: Bantam Books. 
O'Banion, T. (1997). A learning college for the 21st century. Phoenix, AZ: Oryx Press.

Our view - goal of lifelong learning goes all around the clock. (1997, September 22). Traverse City Record-Eagle, p. A6.

Study Group on the Conditions of Excellence in American Higher Education. (1984). Involvement in learning: Realizing the potential of American higher education. Washington, DC: United States Department of Education.

Wingspread Group on Higher Education. (1993). An American imperative-higher expectations for higher education. Johnson Foundation.

\author{
Contacts: \\ Keith Kelly \\ Northwestern Michigan College \\ 1701 East Front Street \\ Traverse City, MI 49686 \\ (616) 922-1312 \\ (616) 922-1546 FAX \\ kkelly@nmc.edu \\ Roberta C. Teahen \\ Northwestern Michigan College \\ 1701 East Front Street \\ Traverse City, MI 49686 \\ (616) 922-1151 \\ (616) 922-1253 FAX \\ rteahen@nmc.edu
}

Keith Kelly, an electronics faculty member with emphasis in microprocessor/microcomputer application development, is the project manager for O.P.E.N. learning and designer/developer of the AIM system. He was also responsible for the complete redesign of the electronics program into an $\mathrm{OE} / \mathrm{OE}$ format four years ago. With a BS in Electrical Engineering Technology from Lake Superior State University, Keith also provides engineering consulting services to local industry for hardware and software control systems.

Roberta Teahen is the Director of the Center for Learning, which, in addition to providing an alternative learning delivery system, also includes many traditional student support services, such as counseling, career planning, employment services, etc. She has served in a variety of leadership positions within NMC and in the community, including many in workforce and economic development. She is a business faculty member and is currently working on a Dissertation for a $\mathrm{PhD}$ in Higher, Adult, and Lifelong Education at Michigan State University. 